\title{
Temperatura base inferior e ciclo de híbridos de canola
}

\author{
Baseline temperature and cycle of canola hibrids
}

\section{Gean Lopes da Luz ${ }^{I}$ Sandro Luis Petter Medeiros ${ }^{\text {II }}$ Gilberto Omar Tomm ${ }^{\text {III }}$ Adriano Bialozor Alan Dischkaln do Amaral ${ }^{\mathrm{II}}$ Dieisson Pivoto ${ }^{\mathrm{II}}$}

\section{RESUMO}

\begin{abstract}
O objetivo do presente trabalho foi determinar a temperatura base inferior $(\mathrm{Tb})$ de dois híbridos de canola durante os subperíodos emergência-início da floração (EMIF), início da floração-final da floração (IF-FF) e final da floração-maturação fisiológica (FF-MF), além da duração em dias de cada subperíodo. Para tanto foi realizado um experimento com nove épocas de semeadura com os híbridos Hyola 61 e Hyola 433 em Santa Maria-RS, sendo utilizados os métodos da menor variabilidade e do desenvolvimento relativo para a determinação da $\mathrm{Tb}$. Observou-se uma relação linear negativa entre temperatura do ar e duração do ciclo em dias. Os valores de $\mathrm{Tb}$ dos genótipos de canola variaram de -0,6 a $9,1^{\circ} \mathrm{C}$ para o método do desenvolvimento relativo e de -1 a $11^{\circ} \mathrm{C}$ pelo método da menor variabilidade. As durações dos subperíodos EM-IF, IF-FF e FF-MF foram, respectivamente, 65, 47 e 24 dias para o híbrido Hyola 61 e 63, 48 e 23 para o híbrido Hyola 433. A duração do ciclo dos dois híbridos diminuiu com o atraso da semeadura, o qual reduziu de 162 para 100 dias no Hyola 433 e de 162 para 100 dias no Hyola 61 .
\end{abstract}

Palavras-chave: Brassica napus L., temperatura do ar, fenologia.

\section{ABSTRACT}

The aim of this study was to determine the lower base temperature $(\mathrm{Tb})$ of two canola hybrids during the subperiods emergency-beginning of flowering (EM-IF), earlyflowering-late flowering (FI-FF) and late-flowering physiological maturity (FF-MF), and the number of days in each subperiod. The experiment was carried out with nine seeding times with the hybrids Hyola 61 and Hyola 433 in
Santa Maria, being utilized two methods to estimate: least deviation and relative development. There was a negative linear relationship between air temperature and cycle length in days. The $\mathrm{Tb}$ values of canola genotypes ranged from -0.6 to $9.1^{\circ} \mathrm{C}$ for relative development method, and -1 to $11^{\circ} \mathrm{C}$ for the least deviation method. The average duration for the subperiods EM-IF, IF-FF and FF-MF were respectively 65, 47 and 24 days for hybrid Hyola 61 and, 68, 48 and 23 days for hybrid Hyola 433. The cycle duration of two hybrids decreased with delayed sowing, which reduced from 162 to 100 days in Hyola 433 and 162 to 104 days in Hyola 61.

Key words: Brassica napus L., air temperature, phenology.

\section{INTRODUÇÃO}

A área cultivada com a cultura da canola (Brassica napus L. var. oleífera) no Brasil vem se expandindo em taxas elevadas nos últimos anos (TOMM et al., 2010). A maioria das plantações brasileiras de canola encontra-se no Rio Grande do Sul e no Paraná, com algumas lavouras em Mato Grosso do Sul. A cultura vem apresentando considerável aumento de área no Brasil, em função da crescente demanda dos setores produtivos, espera-se uma produção de 65,9 mil toneladas para a safra de 2011, em uma área cultivada de 45,8 mil ha (CONAB, 2011).

Entretanto, em virtude, principalmente, de seu cultivo com objetivo industrial ser recente no país,

IUniversidade do Oeste de Santa Catarina (UNOESC), 89820-000, Xanxerê, SC, Brasil. E-mail: gean.luz@unoesc.edu.br. Autor para correspondência.

"Departamento de Fitotecnia, Centro de Ciências Rurais (CCR), Universidade Federal de Santa Maria (UFSM), Santa Maria, RS, Brasil.

IIICentro Nacional de Pesquisa de Trigo, Empresa Brasileira de Pesquisa Agropecuária (Embrapa Trigo), Passo Fundo, RS, Brasil. 
existem poucas as informações sobre as exigências bioclimáticas dos genótipos de canola utilizados no Brasil. Dentre estas exigências está a temperatura base inferior (Tb) de crescimento e a soma térmica para os diferentes subperíodos de desenvolvimento. A determinação destes dois parâmetros é importante como referência na escolha de cultivares a serem utilizadas, na definição de épocas e locais de semeadura, na simulação do desenvolvimento e na estimativa de duração do ciclo das plantas. Apesar de o desenvolvimento depender de vários fatores ambientais, a temperatura do ar é um dos principais elementos meteorológicos que o afetam (GRAMIG \& STOLTENBERG 2007).

A maioria dos trabalhos na cultura da canola cita valor único de Tb para todo o ciclo da cultura. Segundo THOMAS (2003), existe divergência nos resultados de pesquisa quanto à $\mathrm{Tb}$ da canola, sendo que a maioria dos trabalhos indica valores entre $0 \mathrm{e}$ $5^{\circ} \mathrm{C}$. GUERREIRO et al. (2008) compilando dados de experimentos com colza realizados no início dos anos 80, encontraram como Tb o valor de $3,5^{\circ} \mathrm{C}$. MORRISON et al. (1989) determinaram a Tb da canola como sendo $5^{\circ} \mathrm{C}$, sendo este valor utilizado por LAWSON et al. (2006).

A temperatura base inferior de crescimento pode ser determinada por meio de diferentes métodos, sendo mais utilizados o da menor variabilidade e a razão de desenvolvimento (MÜLLER et al., 2009). Para a utilização destes métodos são necessárias observações fenológicas de uma série de épocas de semeaduras ou, de mesma época, mas de locais com condições distintas de temperatura do ar. Contudo, os dados de temperatura base inferior da canola aplicados atualmente nos cálculos fenológicos são retirados da bibliografia internacional, derivados de pesquisas antigas ou com genótipos não utilizados no Brasil.

Dessa forma, o objetivo do presente estudo foi determinar a temperatura base inferior de dois híbridos de canola durante os subperíodos emergênciainício da floração, início da floração-final da floração e final da floração-maturação fisiológica e avaliar as durações dos subperíodos em nove épocas de semeadura.

\section{MATERIAL E MÉTODOS}

O experimento foi realizado no Departamento de Fitotecnia da Universidade Federal de Santa Maria, Santa Maria (UFSM), situada na Depressão Central do Rio Grande do Sul, com coordenadas de 2943'S, $53^{\circ} 43^{\prime} \mathrm{W}$ e altitude de $95 \mathrm{~m}$. O solo é classificado como Argissolo Vermelho distrófico arênico. O clima da região é o Cfa (subtropical úmido com verões quentes e sem estação seca definida), conforme classificação de Köppen.

O delineamento experimental adotado foi o de blocos ao acaso com quatro repetições, com tratamentos distribuídos em esquema fatorial, com dois genótipos, Hyola 61 e Hyola 433, em nove épocas de semeadura, 03/04, 17/04, 01/05, 15/05, 29/05, 12/06, 26/ 06 10/07 e 24/07/2009. TOMM et al. (2010), ressaltam que esses híbridos destacam-se pelos bons rendimentos, com resistência genética à principal doença da cultura da canola, a canela preta (Leptosphaeria maculans, Phoma lingam). As semeaduras foram realizadas manualmente de forma a obter-se 40 plantas $\mathrm{m}^{-2}$ em parcelas constituídas de seis fileiras de plantas com espaçamento de $0,17 \mathrm{~m}$ entre si e $5 \mathrm{~m}$ de comprimento, perfazendo área de $5,1 \mathrm{~m}^{2}$.

As observações fenológicas foram realizadas de acordo com TOMM et al. (2007):

- data de emergência: data em que 50\% das plântulas da parcela emergiram;

- início da floração: data em que 50\% das plantas apresentavam pelo menos uma flor;

- fim da floração: data em que não restarem mais flores, exceto em plantas atípicas;

- data de maturidade: data em que 50\% das sementes mudaram para cor escura nas síliquas localizadas sobre o meio do racemo principal das plantas.

A temperatura base inferior para cada genótipo nos subperíodos emergência-início da floração (EM-IF), início da floração-final da floração (IF-FF) e final da floração-maturação fisiológica (FFMF) foi estimada pelos métodos da menor variabilidade ou desvio padrão e por meio do desenvolvimento relativo conforme ARNOLD (1959), BRUNINI et al. (1976) e GBUR et al. (1979).

A estimativa dos graus-dia (GD) foi obtida pela aplicação das seguintes equações propostas por VILLANOVAet al. (1999):

$\mathrm{GD}=[(\mathrm{Tmax}+\mathrm{Tmin}) / 2]-\mathrm{Tb} \quad($ se $\mathrm{Tb}=\mathrm{Tmin})$, $\mathrm{GD}=(\mathrm{Tmax}-\mathrm{Tb})^{2} /[2(\mathrm{Tmax}-\mathrm{Tmin})] \quad(\mathrm{se} \mathrm{Tb}>\mathrm{Tmin})$, em que, $\mathrm{GD}=$ graus-dia; Tmax e Tmin são as temperaturas máxima e mínima do ar, respectivamente; e Tb é a temperatura base inferior do subperíodo.

A soma térmica acumulada (STa) de cada genótipo foi obtida pelo somatório dos graus-dia acumulados durante o ciclo: STa $=\Sigma$ GD. Os dados da temperatura do ar foram obtidos junto à Estação Climatológica Principal da UFSM, pertencente ao $8^{\circ}$ DISME, localizada a 100m da área experimental.

Na determinação da Tb são escolhidos valores de temperatura a serem empregados na obtenção da soma térmica. O método da menor variabilidade parte da premissa de que o valor atribuído a $\mathrm{Tb}$ 
correspondente ao menor valor do desvio-padrão obtido em dias é considerado como aquele adequado para a cultura em estudo. A expressão utilizada é a seguinte:

$\mathrm{Sd}=(\mathrm{Sdd}) /(\mathrm{T}-\mathrm{Tb})$, em que, $\mathrm{Sd}=$ desviopadrão em dias para série de experimentos; Sdd = desvio-padrão em graus-dia para toda a série de plantio para cada valor de temperatura base inferior; $\mathrm{T}=$ temperatura média para toda série de épocas de semeadura sobre o qual Sdd é baseada (período experimental); $\mathrm{Tb}=$ temperatura base inferior. Foram aplicados valores de $\mathrm{Tb}$ de -3 a $15^{\circ} \mathrm{C}$, com intervalos de $1^{\circ} \mathrm{C}$.

O método do desenvolvimento relativo (DR) consiste em calcular DR por:

$\mathrm{DR}=\mathrm{a}+\mathrm{b}$. Tmed, em que Tmed é a temperatura média $\left({ }^{\circ} \mathrm{C}\right)$; a e b são os coeficientes linear e angular da regressão linear simples. DR é calculado por: $\mathrm{DR}=100 /$ $\mathrm{n}$, no qual DR é o desenvolvimento relativo à temperatura média do ar; 100 representa um valor arbitrário de ponderação; n são os dias do ciclo da cultura.

Quando DR for igual à zero, Tmed será igual a $\mathrm{Tb}$; sendo obtida por: $\mathrm{Tb}=-\mathrm{a} / \mathrm{b}$.

Para a obtenção da temperatura base, calculou-se a média dos valores obtidos pelos dois métodos empregados, baseado na metodologia adotada por FAGUNDES et al. (2010). Os dados referentes às durações dos subperíodos e ciclo foram submetidos ao teste de Tukey a 5\% de probabilidade.

\section{RESULTADOS E DISCUSSÃO}

A influência da temperatura do ar sobre a duração dos subperíodos da cultura canola, em dias (Tabela 1), pode ser verificado na figura 1. O híbrido Hyola 61 apresentou duração do subperíodo EM-IF variando de 52 a 78 dias para médias de temperaturas do ar de 17,7 a $12,8^{\circ} \mathrm{C}$ e para Hyola 433 , essa variação foi de 49 a 76 dias com valores médios temperaturas de 17,8 e $12,9^{\circ} \mathrm{C}$, respectivamente. A duração do subperíodo IF-FF para o híbrido Hyola 61 variou de 34 a 80 dias, com temperaturas médias entre 18,1 e $13^{\circ} \mathrm{C}$ e para o híbrido Hyola 433 a variação foi desse subperíodo foi de 34 a 81 dias com valores de temperaturas de 17,8 e $12,9^{\circ} \mathrm{C}$. No subperíodo FF-MF para o híbrido Hyola 61, observou-se variação na duração de 16 a 31 dias, com temperaturas entre 25,4 e $18,0^{\circ} \mathrm{C}$ e para o híbrido Hyola 433 essa duração variou de 16 a 30 dias, para temperaturas de 26,0 e $18,0^{\circ} \mathrm{C}$ (Figura 1).

Para completar o ciclo, os híbridos de canola Hyola 433 e Hyola 61 necessitaram de 100 a 162 dias e de 104 a 162, respectivamente (Tabela 1). Esses resultados corroboram a afirmação de DALMAGO et al. (2010) de que existe heterogeneidade de respostas da cultura da canola ao ambiente, resultado tanto do manejo agrícola, como por exemplo, de diferentes profundidades de semeadura, quanto de adaptações a variáveis ambientais, como a disponibilidade hídrica e a geada.

Os valores dos coeficientes de variação para as durações dos subperíodos e do ciclo dos dois

Tabela 1 - Duração dos subperíodos emergência - início da floração (EM-IF), início da floração - final da floração (IF-FF) e final da floração-maturação fisiológica (FF-MF) dos híbridos de canola Hyola 433 e Hyola 61 em nove épocas de semeadura. Santa Maria, 2011.

\begin{tabular}{|c|c|c|c|c|c|c|c|c|}
\hline \multirow[b]{2}{*}{ Data de semeadura } & \multicolumn{4}{|c|}{--------------------------Hyola 433------------------------- } & \multicolumn{4}{|c|}{---------------------------Hyola 61------------------------- } \\
\hline & $\begin{array}{l}\text { EM-IF } \\
\text { (Dias) }\end{array}$ & $\begin{array}{l}\text { IF-FF } \\
\text { (Dias) }\end{array}$ & $\begin{array}{c}\text { FF-MF } \\
\text { (Dias) }\end{array}$ & $\begin{array}{l}\text { Ciclo } \\
\text { (Dias) }\end{array}$ & $\begin{array}{r}\text { EM-IF } \\
\text { (Dias) }\end{array}$ & $\begin{array}{l}\text { IF-FF } \\
\text { (Dias) }\end{array}$ & $\begin{array}{c}\text { FF-MF } \\
\text { (Dias) }\end{array}$ & $\begin{array}{l}\text { Ciclo } \\
\text { (Dias) }\end{array}$ \\
\hline 03/04/09 & $58 d$ & $81 \mathrm{a}$ & 23ab & $162 \mathrm{a}$ & 59c & $80 a$ & 23bc & $162 \mathrm{a}$ \\
\hline $17 / 04 / 09$ & $65 c$ & $64 b$ & $22 \mathrm{ab}$ & $151 c$ & $66 b$ & $63 b$ & 22cd & $151 \mathrm{ab}$ \\
\hline 01/05/09 & $75 a$ & $53 c$ & $28 a$ & $156 b$ & $76 a$ & 49c & $30 a$ & $149 b$ \\
\hline 15/05/09 & $76 a$ & $41 \mathrm{~d}$ & $28 a$ & $145 d$ & $78 a$ & 41de & 28ab & $147 b$ \\
\hline 29/05/09 & $68 b$ & $35 d$ & $30 a$ & 133e & $69 b$ & 35de & $31 a$ & $135 c$ \\
\hline $12 / 06 / 09$ & $66 \mathrm{dc}$ & $34 d$ & $29 a$ & $129 f$ & $68 b$ & $34 \mathrm{e}$ & $29 a$ & $131 c$ \\
\hline 26/06/09 & 59d & $42 d$ & $16 \mathrm{~b}$ & $117 \mathrm{~g}$ & $60 c$ & 42cd & $16 \mathrm{~d}$ & 119d \\
\hline $10 / 07 / 09$ & $54 \mathrm{e}$ & 43cd & $16 b$ & $113 \mathrm{~g}$ & $57 c$ & 40de & $16 \mathrm{~d}$ & 113de \\
\hline 24/07/09 & $49 f$ & $36 \mathrm{~d}$ & $16 b$ & $100 \mathrm{~h}$ & $52 d$ & 35de & $17 \mathrm{~cd}$ & $104 \mathrm{e}$ \\
\hline Média & 63 & 48 & 23 & 134 & 65 & 47 & 24 & 147 \\
\hline CV (\%) & 2,05 & 8,54 & 18,44 & 1,47 & 2,49 & 6,53 & 10,81 & 3,53 \\
\hline
\end{tabular}

Médias não seguidas pela mesma letra na coluna diferem pelo teste de Tukey a 5\% de probabilidade.

Ciência Rural, v.42, n.9, set, 2012. 


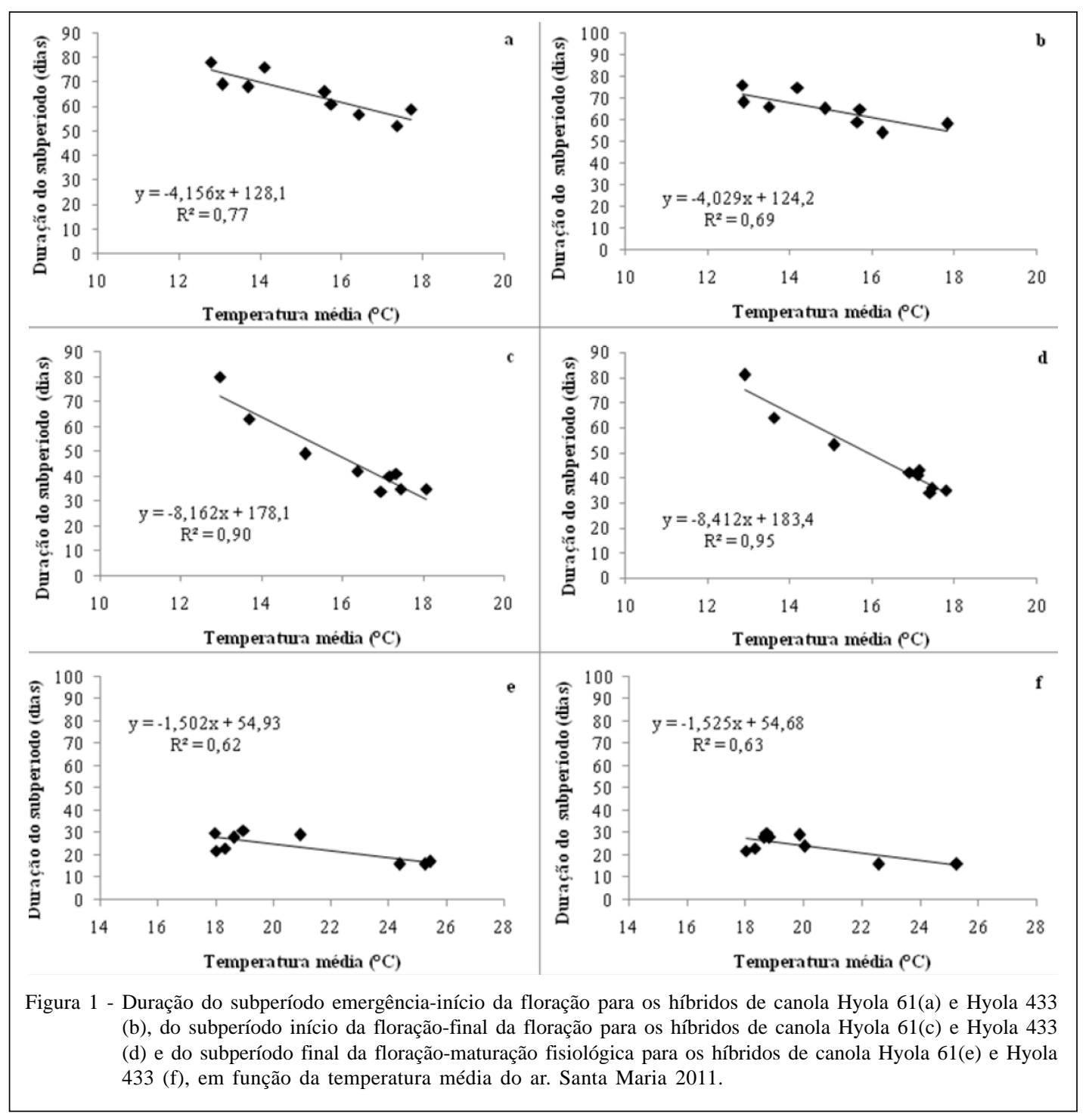

híbridos podem ser considerados baixos (Tabela 1), exceto para o subperíodo final da floração à maturação fisiológica, os quais foram elevados. Esse aumento do coeficiente de variação foi decorrente da forma de determinação do ponto de maturação fisiológica, o qual foi obtido visualmente através da coloração escura das síliquas, conforme preconizam TOMM et al. (2007). Assim, essa determinação visual pode ser a explicação do aumento do referido coeficiente. Observou-se tendência de diminuição da duração dos subperíodos e do ciclo com o avanço da época de semeadura, sendo que as primeiras épocas foram significativamente superiores às demais, principalmente para a duração do ciclo.

A presença de uma relação linear negativa entre temperatura do ar e a duração indica que a diminuição da temperatura do ar determina um aumento das durações do ciclo e subperíodos para os dois genótipos (Figura 1). Além disso, a análise de regressão evidencia maiores valores de coeficiente angular para o subperíodo IF-FF, indicando que o mesmo foi mais sensível à temperatura do ar que o subperíodo EM-IF, porém menos sensível que o FF-MF. Esses resultados corroboram com a afirmação de KERBER et al. (2009), de que a canola cultivada no Brasil apresenta maior resposta à temperatura do ar (soma térmica).

A interferência da temperatura do ar sobre as durações dos subperíodos também foram constatadas em outras culturas. VIEIRA et al. (1990) afirmaram que a temperatura média do ar afeta a duração dos subperíodos da cultura do feijão, porém, destacam 
que o subperíodo mais influenciado é o da EM-IF. MUNDSTOCK (1983) ressalta que a ação da temperatura do ar nos cereais de inverno é mais efetiva, principalmente na duração do período compreendido entre a emergência e o florescimento. O mesmo ocorre no milho, pois FANCELLI \& DOURADO NETO (2004) citam que se aplica a diferença de soma térmica do subperíodo EM-IF para diferenciação dos híbridos por precocidade..

Esse comportamento verificado em outras culturas não se repete na canola, pois o subperíodo mais sensível foi IF-FF (Figuras 1d e 1e). Resultado que corrobora os de TOMM et al. (2010), os quais obtiveram que a duração do subperíodo EM-IF variou entre 50 e 68 dias e para o subperíodo IF-FF a duração dobrou em resposta à época de semeadura, variando de 22 a 44 dias, para a canola cultivada em sete épocas de semeadura em Maringá, PR. Possivelmente, o fator responsável pela variação das durações dos subperíodos encontrados pelos referidos autores tenha sido a temperatura do ar, como constado na figura 1.

Os valores de $\mathrm{Tb}$ dos genótipos de canola ficaram entre -1 e $11^{\circ} \mathrm{C}$ para o método da menor variabilidade e entre $-0,6$ e $9,1^{\circ} \mathrm{C}$ pelo método do desenvolvimento relativo, variando de acordo com o híbrido e o subperíodo estudado (Tabela 2). Assim, para cada subperíodo considerado deve ser utilizado um valor adequado de Tb. Para o subperíodo EM-IF da cultura da canola, HODGSON (1978) encontrou a Tb de $0,4^{\circ} \mathrm{C}$, valor próximo aos $-0,8$ e $0,3^{\circ} \mathrm{C}$ determinados neste trabalho para os híbridos Hyola 61 e Hyola 433 (Tabela 2), respectivamente. A importância da determinação da $\mathrm{Tb}$ ao longo do ciclo foi citada por STRECK et al. (2005), os quais afirmam que a temperatura base depende do genótipo e do subperíodo de desenvolvimento analisados.
A maior variação encontrada entre os valores de Tb obtidos com os métodos de determinação foi observada no subperíodo IF-FF para o híbrido Hyola 433, com valor de $2,2^{\circ} \mathrm{C}$ (Tabela 2). FAGUNDES et al. (2010) obtiveram uma diferença máxima de $3,3^{\circ} \mathrm{C}$ entre os métodos de análise, na determinação da Tb de Aspilia montevidensis. Determinando a Tb para três cultivares de triticale, PEDRO JÚNIOR, et al. (2004) obtiveram diferença máxima de $0,5^{\circ} \mathrm{C}$ entre os métodos do desenvolvimento relativo e da menor variabilidade. Resultado semelhante foi observado por CARGNELUTTI FILHO et al. (2005), estimando a Tb inferior de 19 genótipos de feijão, com diferenças entre os dois métodos variando entre 0,2 a $1,8^{\circ} \mathrm{C}$.

Observou-se que, independentemente do híbrido analisado, a Tb é menor no subperíodo EM-IF, com valor próximo de $0^{\circ} \mathrm{C}$. No subperíodo seguinte, a temperatura base se elevou para próximo a $10^{\circ} \mathrm{C}$, reduzindo esse valor em 2 a $3^{\circ} \mathrm{C}$ no subperíodo FF-MF (Tabela 2). A variação da Tb de acordo com o subperíodo fenológico também foi observada por FAGUNDES et al. (2010) e GONÇALVES et al. (2008).

Os valores de Tb e soma térmica podem ser úteis para fins de zoneamento e planejamento agrícola, como por exemplo, na delimitação de áreas aptas quanto a exigência térmica, determinação de épocas de semeadura mais adequadas e previsão das datas de ocorrência dos diferentes subperíodos e da duração do ciclo da cultura.

\section{CONCLUSÃO}

Existe uma relação linear negativa entre a temperatura do ar e a duração dos subperíodos (em dias) para os híbridos de canola Hyola 61 e Hyola 433. Assim, as semeaduras mais tardias determinam

Tabela 2 - Estimativa da temperatura base inferior por dois métodos (Menor variabilidade e Desenvolvimento relativo), equações de regressão e coeficiente de determinação $\left(\mathrm{R}^{2}\right)$ pelo método do Desenvolvimento relativo, para dois híbridos de canola durante os subperíodos emergência-início da floração (EM-IF), início da floração-final da floração (IF-FF) e final da floração-maturação fisiológica (FF-MF). Santa Maria, 2011.

\begin{tabular}{|c|c|c|c|c|c|}
\hline \multirow{2}{*}{ Subperíodo } & \multirow{2}{*}{ Genótipos } & \multirow{2}{*}{$\begin{array}{c}\text { Temperatura Base }\left({ }^{\circ} \mathrm{C}\right) \\
\text { Menor variabilidade }\end{array}$} & \multicolumn{2}{|r|}{ Equação } & \multirow{2}{*}{ Média } \\
\hline & & & & Desenvolvimento relativo & \\
\hline EM-IF & Hyola 61 & -1 & $-0,6$ & $\mathrm{Y}=0,098 \mathrm{X}+0,062 \mathrm{r}^{2}=0,70 *$ & $-0,8$ \\
\hline EM-IF & Hyola 433 & 0 & 0,6 & $\mathrm{Y}=0,114 \mathrm{X}+0,067 \mathrm{r}^{2}=0,72 *$ & 0,3 \\
\hline IF-FF & Hyola 61 & 11 & 9,1 & $\mathrm{Y}=0,326 \mathrm{X}-2,961 \mathrm{r}^{2}=0,92^{*}$ & 10 \\
\hline IF-FF & Hyola 433 & 11 & 8,8 & $Y=0,300 X-2,64 r^{2}=0,93^{*}$ & 9,9 \\
\hline FF-MF & Hyola 61 & 7 & 7,4 & $\mathrm{Y}=0,335 \mathrm{X}-2,472 \mathrm{r}^{2}=0,73^{*}$ & 7,2 \\
\hline FF-MF & Hyola 433 & 8 & 7,8 & $Y=0,357 X-2,773 r^{2}=0,74 *$ & 7,9 \\
\hline
\end{tabular}

*Significativo a 5\% de probabilidade de erro pelo teste F. 
diminuição do ciclo dos dois híbridos, o qual reduz de 162 até 100 dias para o Hyola 433 e de 162 até 100 dias para Hyola 61. O efeito da temperatura do ar no aumento da duração dos subperíodos é mais marcante na floração (IF-FF) da cultura da canola. Os valores de temperatura base inferior estimados para os subperíodos emergência - início de floração, início e final da floração e final da floração até a maturação fisiológica são de -0,8, 10 e 7,2 ${ }^{\circ} \mathrm{C}$ para o híbrido Hyola 61 e de 0,3, 9,9 e 7,9 ${ }^{\circ} \mathrm{C}$ para o híbrido Hyola 433, respectivamente. Para os mesmos subperíodos, as durações médias são de 63, 48 e 23 dias para o híbrido Hyola 433 e de 65, 47 e 24 dias para o híbrido Hyola 61, respectivamente.

\section{AGRADECIMENTO}

Ao Conselho Nacional de Desenvolvimento Científico e Tecnológico pela concessão de bolsas de iniciação científica, doutorado e produtividade em pesquisa.

\section{REFERÊNCIAS}

ARNOLD, C.Y. The determination and significance of the base temperature in a linear heat unit system. Journal of American Society Horticultural Science, Geneva, v.74, n.1, p.430445, 1959.

BRUNINI, O. et al. Temperatura-base para alface cultivar "White Boston”, em um sistema de unidades térmicas. Bragantia, Campinas, v.35, n.19, p.213-219, 1976.

CARGNELUTTI FILHO, A. et al. Determinação da temperatura base e graus-dia para cultivares de feijão. In: CONGRESSO NACIONAL DE PESQUISA DE FEIJÃO, 8., 2005, Goiânia, Go. Anais... Goiânia: Embrapa Arroz e Feijão, 2005. v.2, p.1136-1139.

CONAB. Companhia Nacional de Abastecimento. Canola, Período: Setembro de 2011. Conjuntura Mensal. 2011. 8p. Disponível em: <http://www.conab.gov.br/OlalaCMS/uploads/ arquivos/11_10_13_09_12_14_canolasetembro2011.pdf $>$. Acesso em: 03 nov. 2011).

DALMAGO, G.A. et al. Aclimatação ao frio e dano por geada em canola. Pesquisa agropecuária brasileira, Brasília, v.45, n.9, p.933-943, 2010. Disponível em: <http://www.scielo.br/ pdf/pab/v45n9/a01v45n9.pdf $>$. Acesso em: 20 jan. 2011. doi: 10.1590/S0100-204X2010000900001.

FAGUNDES, J.D. et al. Temperatura-base e soma térmica de subperíodos do desenvolvimento de Aspilia montevidensis. Bragantia, Campinas, v.69, n.2, p.449-507, 2010. Disponível em: <http://www.scielo.br/pdf/brag/v69n2/30.pdf>. Acesso em: 20 jan. 2011. doi: 10.1590/S0006-87052010000200030.

FANCELli, A.L.; DOURADO NETO, D. Produção de milho. Guaíba: Agropecuária, 2004. 360p.

GBUR, E.E. et al. Use of segmented regression in determination of the base-temperature in heat accumulation models. Agronomy Journal, Madison, v.71, p.949-953, 1979.
GONÇALVES, C. et al. Fenologia e estimativa da duração do ciclo da zínia 'Profusion Cherry' cultivada em vasos em ambiente protegido. Bragantia, Campinas, v.67, n.2, p.527-532, 2008. Disponível em: <http://www.scielo.br/pdf/brag/v67n2/a30v67n2.pdf>. Acesso em: 18 dez. 2010. doi: 10.1590/S0006-87052008000200030.

GRAMIG, G.G.; STOLTENBERG, D.E. Leaf appearance base temperature and phyllochron for common grass and broad leaf weed species. Weed Technology, Champaign, v.21, n.1 p.249254, 2007. Disponível em: <http://wssajournals.org/doi/pdf/ 10.1614/WT-06-0391>. Acesso em: 13 dez. 2010. doi: 10.1614/ WT-06-039.1.

GUERREIRO, J.C. et al. Temperatura base e graus-dia para a colza - síntese de resultados. In: MOSTRA DE INICIAÇÃO CIENTÍFICA DA EMBRAPA TRIGO, 4., 2008, Passo Fundo, RS. Resumos... Passo Fundo: Embrapa Trigo, 2008. Disponível em: <http://www.cnpt.embrapa.br/biblio/do/p_do94.htm>. Acesso em: 22 nov. 2010.

HODGSON, A.S. Rapeseed adaptation in northern New South Wales. II. Predicting plant development of Brassica campestris L' and Brassica napus L. and its influence for planting time' designed to avoid water deficit and frost. Australian Journal of Agriculture Research, Melbourne, v.29, p.711-726, 1978.

KERBER, T.L. et al. Soma térmica de subperíodos de desenvolvimento da canola. In: MOSTRA DE INICIAÇÃO CIENTÍFICA DA EMBRAPA TRIGO, 5., 2009, Passo Fundo, RS. Resumos... Passo Fundo: Embrapa Trigo, 2009. 1p. Disponível em: <http://www.cnpt.embrapa.br/biblio/do/ p_do115_18.htm>. Acesso em: 12 jan. 2011.

LAWSON, A.N. et al. Emergence timing of volunteer canola in spring wheat fields in Manitoba. Weed Science, Lawrence, v.54, n.5, p.873-882, 2006. Disponível em: <http://wssajournals.org/doi/pdf/10.1614/WS-05-169.I.1>. Acesso em: 12 jan. 2011. doi: 10.1614/WS-05-169.I.1.

MORRISON, M.J. et al. The determination and verification of a baseline temperature for the growth of Westar summer rape. Canadian Journal of Plant Science, Ottawa, v.69, p.455464, 1989.

MÜLLER, L. et al. Temperatura base inferior e estacionalidade de produção de genótipos diplóides e tetraplóides de azevém. Ciência Rural, Santa Maria, v.39, n.5 p.1343-1348, 2009. Disponível em: <http://www.scielo.br/pdf/cr/v39n5/ a192cr1172.pdf $>$. Acesso em: 23 out. 2010. doi: 10.1590/ S0103-84782009005000098.

MUNDSTOCK, C.M. Cultivo dos cereais de estação fria. Porto Alegre: NBS, 1983. 265p.

PEDRO JÚNIOR., M.J. et al. Temperatura-base, grau-dia e duração do ciclo para cultivares de triticale. Bragantia, Campinas, v.63, n.3, p.447-453, 2004. Disponível em: <http:/ /www.scielo.br/pdf-/brag/v63n3/22643.pdf>. Acesso em: $18 \mathrm{dez}$. 2010. doi: 10.1590/S0006-87052004000300015.

THOMAS, P. Canola growers' manual. Winnipeg: Canola Council of Canada, 2003. Disponível em: <http://www.canolacouncil.org/manual>. Acesso em: 12 nov. 2010.

TOMM, G.O. Indicativos tecnológicos para produção de canola no Rio Grande do Sul. Passo Fundo: Embrapa Trigo, 2007. 68p. 
TOMM, G.O. et al. Efeito de épocas de semeadura sobre o desempenho de genótipos de canola de ciclo precoce e médio, em Maringá, Paraná. Passo Fundo: Embrapa Trigo, 2010. 13p. Disponível em: <http://www.cnpt.embrapa.br/biblio/ bp/p_bp75.htm>. Acesso em: 12 nov. 2010.

STRECK, N.A. et al. Estimativa do plastocrono em meloeiro (Cucumis melo L.) cultivado em estufa plástica em diferentes épocas do ano. Ciência Rural, Santa Maria, v.35, n.6, p.12751280, 2005. Disponível em: <http://www.scielo.br/ scielo.php?script=sci_text\&pid=S01082005060008 - \&lng=pt\&nrm=iso $>$. Acesso em: 17 nov. 2009. doi: 10.1590/ S0103847820050006-00008.

VIEIRA, H.J. et al. Disponibilidade hídrica do solo e eficiência do feijoeiro em utilizar água e radiação solar. Pesquisa Agropecuária Brasileira, Brasília, v.25, n.10, p.1249-1445, 1990

VILLA NOVA, N.A. et al. Modelo para a previsão da produtividade do capim elefante em função de temperatura do ar, fotoperíodo e freqüência de desfolha. Revista Brasileira de Agrometeorologia, Santa Maria, v.7, n.1, p.75-79, 1999. 